\title{
The Application of Bioreactors for Cartilage Tissue Engineering: Advances, Limitations, and Future Perspectives
}

\author{
Liwei Fu, ${ }^{1,2}$ Pinxue Li, ${ }^{1,2}$ Hao Li, ${ }^{1,2}$ Cangjian Gao, ${ }^{1,2}$ Zhen Yang, ${ }^{1,2}$ Tianyuan Zhao,, \\ Wei Chen, ${ }^{1,2}$ Zhiyao Liao, ${ }^{1,2}$ Yu Peng, ${ }^{2}$ Fuyang Cao, ${ }^{1}$ Xiang Sui, ${ }^{1}$ Shuyun Liu, ${ }^{1}$ \\ and Quanyi Guo $\mathbb{D}^{1,2}$ \\ ${ }^{1}$ Institute of Orthopedics, Chinese PLA General Hospital, Beijing Key Laboratory of Regenerative Medicine in Orthopedics, \\ Key Laboratory of Musculoskeletal Trauma \& War Injuries PLA, No. 28 Fuxing Road, Haidian District, Beijing 100853, China \\ ${ }^{2}$ School of Medicine, Nankai University, Tianjin 300071, China \\ Correspondence should be addressed to Quanyi Guo; doctorguo_301@163.com
}

Received 15 November 2020; Revised 30 December 2020; Accepted 11 January 2021; Published 21 January 2021

Academic Editor: Dunfang Zhang

Copyright ( 92021 Liwei Fu et al. This is an open access article distributed under the Creative Commons Attribution License, which permits unrestricted use, distribution, and reproduction in any medium, provided the original work is properly cited.

\begin{abstract}
Tissue engineering (TE) has brought new hope for articular cartilage regeneration, as TE can provide structural and functional substitutes for native tissues. The basic elements of TE involve scaffolds, seeded cells, and biochemical and biomechanical stimuli. However, there are some limitations of TE; what most important is that static cell culture on scaffolds cannot simulate the physiological environment required for the development of natural cartilage. Recently, bioreactors have been used to simulate the physical and mechanical environment during the development of articular cartilage. This review aims to provide an overview of the concepts, categories, and applications of bioreactors for cartilage TE with emphasis on the design of various bioreactor systems.
\end{abstract}

\section{Introduction}

The regeneration of articular cartilage (AC) is one of the challenges in regenerative medicine due to its poor regenerative capacity $[1,2]$. Natural AC is a complex hierarchical structure that is avascular with four layers: the surface zone, middle zone, deep zone, and calcified zone [3]. These zones have different biochemical compositions, chondrocyte phenotypes, and physiological characteristics tied directly to the effects of mechanical loading and the physiological environment $[4,5]$. The current clinical treatment strategies mainly include arthroscopic debridement, microfracture, and autogenous osteochondral transplantation, which can promote tissue recovery to some extent, but the quality and long-term repair effect of regenerated tissue are not satisfactory $[1,6,7]$.

Tissue engineering has brought new hopes for $\mathrm{AC}$ regeneration, as it can provide structural and functional substitutes for native tissues $[8,9]$. The basic elements of tissue engineering involve scaffolds, seed cells, and biochemical and biomechanical stimuli $[10,11]$. According to the presence of seeded cells, scaffolds can be divided into cellular scaffolds and cell-free scaffolds [12]. There have been many studies on the three-dimensional porous biodegradable structure of scaffolds for chondrocyte or mesenchymal stem cell (MSC) seeding $[13,14]$. However, there are many limitations of cell-seeded scaffolds, one of the most important being that static cell culture on scaffolds cannot simulate the physiological environment required for the development of natural cartilage [15]. For example, in addition to the uneven delivery of oxygen and nutrients, the associated lack of mechanical stimulation causes decreased proliferation and differentiation and results in nonuniform cell distribution. For optimal AC repair, tissue-engineered cell-seeded scaffolds should be structurally and functionally similar to normal AC, and the surrounding physiological environment that can influence chondrogenesis should be modeled [16, 17]. The environment includes hydrostatic pressure; fluid shear force; microgravity; sound waves; magnetic field; and biochemical conditions, such as the $\mathrm{pH}, \mathrm{CO} 2$, and $\mathrm{pO} 2$ 
levels; temperature; and growth factors. Therefore, traditional cell culture techniques cannot meet the requirements of AC tissue engineering, and complex bioreactors have recently been used to simulate the physical and mechanical environment that influences chondrogenesis $[3,18,19]$. Bioreactors are powerful dynamic culture model systems that can apply a combination of chemical, mechanical, electrical, and/or magnetic stimulation to study the basic mechanisms of cell function under physiologically related conditions within seeded cells and to facilitate the correct development of tissue [20,21].

The aim of this review is to summarize the bioreactors that have been applied in tissue engineering articular cartilage (TEAC). In detail, we introduce the common categories and important design principles of bioreactors. In addition, we discuss the combinations between bioreactors and some techniques, such as $3 \mathrm{D}$ printing and microcarriers. Subsequently, we consider the challenges and future prospects for bioreactors in TEAC.

\section{Common Types of Bioreactors}

An ideal bioreactor should have several necessary functions, including enhancing the expansion of seeded cells, promoting the exchange of nutrients and oxygen, and providing appropriate physicochemical stimuli $[16,19]$. Currently, the most common types of bioreactors are spinner flasks, rotating wall vessels, and perfusion systems [19]. Moreover, with the development of TEAC, some novel bioreactors that provide noncontact biomechanical loads have been designed, such as magnetic bioreactors and ultrasonic bioreactors. The application of these bioreactors (as shown in Table 1) aims to simulate the complex physiological and biomechanical environments in AC [3].

2.1. Spinner Flasks (SFs). An SF is a cylindrical culture system that includes two arms used to remove the stumps and a bottom stirring system to mix the culture medium (Figure 1(a)) $[19,22]$. Scaffolds are mostly hung from the top of the flask with a needle or thread. SF bioreactors can create fluid convection and hydrodynamics that enhance the efficiency of nutrient delivery and seeding of cells in the scaffold. Moreover, numerous studies have shown that SFs can be used in AC tissue engineering for AC tissue formation and cell function $[19,23]$. For example, Yoon et al. used SFs to culture cartilage formation of human ADSCs (hADSCs), which were induced toward spheroid formation and chondrogenic differentiation on a large scale. The results showed that chondrogenic differentiation in vitro and subsequent chondrogenic formation in vivo of hADSCs in the spherical culture system was enhanced compared with those in monolayer culture. Therefore, the SF was found to promote the chondrogenic differentiation of hADSCs in the experiment, and its function in the large-scale culture of cells in AC tissue engineering was also verified [24]. In another study, Xu et al. applied SFs in association with chondrocyte seeding on alginate gel beads. It was suggested that $3 \mathrm{D}$ dynamic culture can provide a suitable system supporting both differentiation and redifferentiation of chondrocytes [23].
Although SFs present some advantages in the delivery of medium when compared with static culture, the degree of delivery is far from sufficient, and the shear force produced by the fluid can also adversely affect the cells.

2.2. Rotating Wall Vessels ( $R W V s$ ). RWVs consist of a pair of concentric cylinders: rotating outer cylinders to hold scaffolds or cells and inner cylinders that are static and used to exchange gases (Figure 1(b)) [19, 22]. Compared with spinner flasks, RWVs create a microgravity environment and provide controlled oxygen transport, as well as low shear forces and turbulence. For instance, Zhu et al. developed a cell-hydrogel cartilage construct in a dynamic RWV. The results suggested that the mass transfer efficiency of RWVs was greater than that of static culture conditions in achieving final equilibrium [25]. In another study, Nordberg et al. investigated how simulated microgravity and cyclic hydrostatic pressure modulate chondrocyte homeostasis, specifically focusing on the effects of these mechanical stimuli on LRP4/5/6 expression, which has been shown to be essential for maintaining the balance between bone formation and resorption. They simulated rat chondrosarcoma cell (RCS) pellets under cyclic hydrostatic pressure $(1 \mathrm{~Hz}, 7.5 \mathrm{MPa}$, $4 \mathrm{~h}$ /day) or simulated microgravity in an RWV bioreactor. The experimental results showed that the growth of RCS particles was regulated by mechanical stimulation and that the expression of LRP4/5/6 in chondrocytes was affected under cyclic hydrostatic pressure or microgravity [26]. However, when the density and size of cells reach a certain level, collisions between the cells and the inside and outside walls of the RWV are inevitable. The collisions potentially induce large shear stresses that may be destructive to the cells in tissue engineering.

2.3. Perfusion Bioreactors. As described above, SFs and RWVs are not able to effectively infuse the medium into the scaffold. To overcome the limitations described, flow perfusion has been used for the regeneration of AC. Perfusion bioreactors use a pumping system to feed medium directly to scaffolds. Most of them consist of a pump, a culture media reservoir, a tubing circuit, and a perfusion cartridge that holds the scaffolds (Figure 1(c)) [20, 21]. The perfusion cartridge is one of the most important components that needs to be customized according to the properties of the scaffolds so that the medium can be injected directly into the scaffold instead of flowing around it. Moreover, the scaffold also needs to have highly connected pores. Recently, many perfusion bioreactors have been developed and applied in tissue-engineered cartilage. For example, Theodoridis et al. prepared a porous 3D-printed PCL scaffold and seeded it with adipose MSCs. Then, the scaffolds were cultured in a static culture and perfusion bioreactor, and the results showed that dynamic culture favored chondrogenic differentiation and achieved better penetration of cells within the scaffold than static culture [27]. In addition, Pigeot et al. used a perfusion bioreactor to culture human mesenchymal stem cells (hMSCs) seeded on collagen sponges and showed that a large amount of apoptosis-devitalized hypertrophic 
TABLE 1: Compilation of studies that investigated the responses of seeded cells under various bioreactors.

\begin{tabular}{|c|c|c|c|c|}
\hline Authors & Cell source & Study design & $\begin{array}{l}\text { Type of } \\
\text { bioreactor }\end{array}$ & Results \\
\hline $\mathrm{Xu}$ et al. [23] & Chondrocytes & Alginate gel beads with chondrocytes & $\begin{array}{l}\text { Spinner } \\
\text { flasks }\end{array}$ & $\begin{array}{l}\text { Improved the GAG quantification and } \\
\text { relevant gene expression }\end{array}$ \\
\hline Yoon et al. [24] & hADSCs & $\begin{array}{c}\text { Cellular metabolic response to } \\
\text { dynamic loading }\end{array}$ & $\begin{array}{l}\text { Spinner } \\
\text { flasks }\end{array}$ & $\begin{array}{c}\text { Enhanced chondrogenic differentiation of } \\
\text { hADSCs }\end{array}$ \\
\hline Zhu et al. [25] & hADSCs & $\begin{array}{l}\text { Chitosan/gelatin hybrid hydrogel } \\
\text { and subsequent dynamic loading }\end{array}$ & $\begin{array}{l}\text { Rotating } \\
\text { wall vessels }\end{array}$ & Enhanced proliferation and matrix secretion \\
\hline Nordberg et al. [26] & RCS & Culture of cell pellets & $\begin{array}{c}\text { Rotating } \\
\text { wall vessels }\end{array}$ & $\begin{array}{l}\text { Mechanical stimulation influenced the } \\
\text { expression of LRP } 4 / 5 / 6 \text { in chondrocytes }\end{array}$ \\
\hline Theodoridis et al. [27] & hADSCs & 3D-printed PCL scaffolds seeded cells & $\begin{array}{l}\text { Perfusion } \\
\text { bioreactors }\end{array}$ & $\begin{array}{l}\text { Achieved better penetration and uniform } \\
\text { distribution of the cells within the scaffold }\end{array}$ \\
\hline Pigeot et al. [28] & hBM-MSCs & $\begin{array}{l}\text { Human MSCs cultured in the } \\
\text { perfusion bioreactor }\end{array}$ & $\begin{array}{l}\text { Perfusion } \\
\text { bioreactors }\end{array}$ & $\begin{array}{c}\text { Generated a homogeneous hypertrophic } \\
\text { cartilage ECM; efficiently induced towards } \\
\text { apoptosis }\end{array}$ \\
\hline Dikina et al. [31] & hBM-MSCs & $\begin{array}{l}\text { Scaffold-free human mesenchymal } \\
\text { stem cell sheets in response to } \\
\text { variable magnetic fields }\end{array}$ & $\begin{array}{c}\text { Magnetic } \\
\text { bioreactors }\end{array}$ & Did not affect cartilage formation \\
\hline Thakurta et al. [34] & Chondrocytes & Chondrocyte-seeded scaffolds & $\begin{array}{r}\text { Ultrasonic } \\
\text { bioreactors }\end{array}$ & $\begin{array}{l}\text { Ultrasonic stimulation significantly impacted } \\
\text { cell proliferation and depth-independent cell } \\
\text { population density }\end{array}$ \\
\hline Subramanian et al. [36] & Chondrocytes & $\begin{array}{l}\text { Studying the response of cells to } \\
\text { ultrasonic stimulation }\end{array}$ & $\begin{array}{l}\text { Ultrasonic } \\
\text { bioreactors }\end{array}$ & $\begin{array}{c}\text { Positively influenced several factors, } \\
\text { including cell proliferation, viability, and } \\
\text { gene expression of select chondrocytic } \\
\text { markers }\end{array}$ \\
\hline
\end{tabular}

(a)

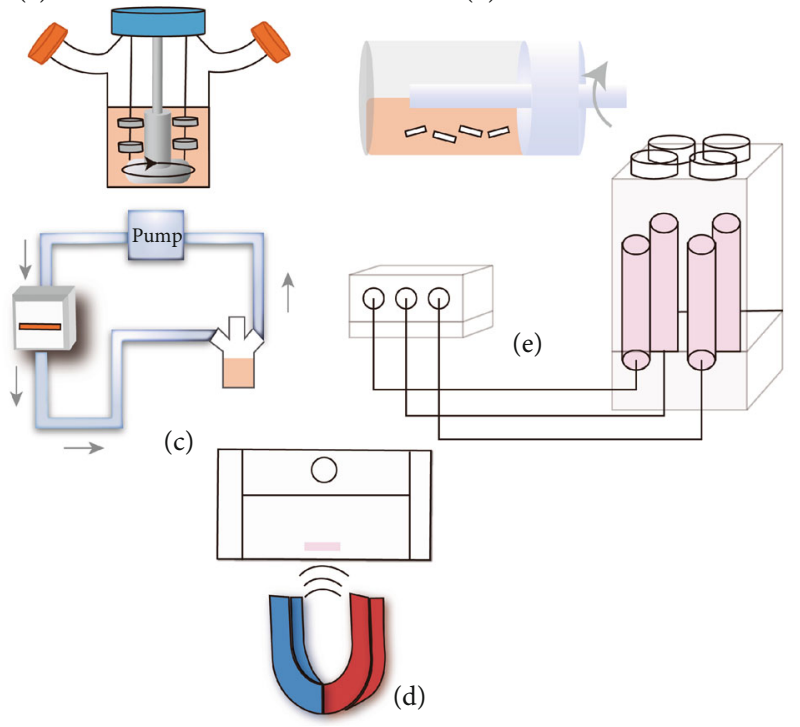

Figure 1: Common bioreactors for tissue engineering. (a) Spinner flask. (b) Rotating wall vessel. (c) Direct perfusion. (d) Magnetic bioreactor. (e) Ultrasonic bioreactors.

cartilage extracellular matrix (ECM) could be engineered using bioreactor systems [28].

2.4. Magnetic Bioreactors. The three bioreactors mentioned above mainly use mechanical stimuli on a macroscopic scale, such as hydrostatic pressure, shear force, tensile force, and compression force, which are directly applied to tissues or scaffolds to guide the behavior of cells. The limitations are the smaller range of stimuli and disadvantages of open culture conditions. Therefore, microscale mechanobiological techniques such as magnetic forces have been studied. Recent studies have found that magnetic fields affect cells, tissues, and entire organisms, including the formation of the extracellular matrix of hyaline cartilage, proliferation of bovine chondrocytes, and the synthesis of proteoglycan [29, 30]. Magnetic field bioreactors are advantageous, because they can meet the requirement of sterile culture conditions by contactless culture $[31,32]$. Most of them consist of one or a group of permanent magnets that influence the behavior of cells through static or dynamic magnetic field strengths (Figure 1(d)). In addition, advanced magnetic bioreactors were designed according to the physical principles describing translational and rotational motion of magnetic particles, ferrofluids, and materials in high-gradient magnetic fields [33]. For example, Brady et al. constructed a novel highthroughput magnetomechanical stimulation bioreactor. Validation tests showed that the bioreactor provided a unique platform for researchers to study the combined effects of electrical phenomena and mechanical stimulation [32]. In another study, however, Dikina et al. investigated a variable magnetic field bioreactor composed of permanent magnets that were used for the culture of scaffold-free, high-density hMSC sheets, and the results showed that the bioreactor did not enhance chondrogenesis in the cell-only sheets. Therefore, more studies should be performed to validate 
the enhanced ability of chondrogenesis in response to magnetic fields [31].

2.5. Ultrasonic Bioreactors. Ultrasonic stimulation has also been shown to influence cell growth in some cases. In particular, low-intensity continuous ultrasound (US) has been shown to modulate the expression of chondrocyte-specific genes $[34,35]$. The traditional ultrasonic bioreactor is realized by adding an ultrasonic processing system. With the development of technology, various ultrasonic bioreactors have been designed. Subramanian et al. designed a representative US-assisted bioreactor (Figure 1(e)). They placed a plate holder which retains the six-well plates with scaffolds above the transducer array. A custom splitter which allows manipulation of the ultrasound (US) signal makes all wells have identical pressure profiles. This apparatus is then used to stimulate chondrocyte maintenance. The tests showed that the bioreactor had positive effects on cell proliferation, viability, and selection of chondrocyte markers for gene expression [36]. In another study, Thakurta et al. placed chondrocyteseeded scaffolds in the same US-assisted bioreactor, which supplied resonance frequencies $(\sim 5.0 \mathrm{MHz})$. The results showed that the COL2A1/COL1A1 ratios, ACAN mRNA, and the expression of Sox-9 were elevated compared to controls [34].

hADSCs: human adipose-derived stem cells; RCS: rat chondrosarcoma cells; hBM-MSCs: human bone marrowderived mesenchymal stromal cells; PCL: polycaprolactone.

\section{Considerations for Seeded Cells in Bioreactor Design}

As a dynamic and static combination of three-dimensional cell culture device, bioreactor can simulate the microenvironment of cartilage in vivo and provide suitable external conditions for the construction of tissue-engineered cartilage by regulating the biophysical factors of seed cells. In this section, the latest development of bioreactors under different biophysical factors and the detailed design elements are described from the aspects of oxygen concentration, mechanical stimulation, and noncontact physical stimulation (as shown in Table 2), which are expected to provide some reference for the design of bioreactor.

3.1. Oxygen. Cartilage is already exposed to relatively low levels of oxygen during the initial stages of embryonic development. Therefore, studies have been conducted on the role of oxygen tension in cartilage formation. Numerous studies have shown that the biochemical components of cartilage in vitro are more similar to natural tissue when cultured under hypoxic conditions $[37,38]$. Therefore, it is necessary to determine the standardized oxygen concentration in the bioreactor design. Increasing evidence has demonstrated that low oxygen tension promotes cell proliferation [39], enhances chondrogenic differentiation capacity [40], and increases migration ability [41] but inhibits osteogenic differentiation [42]. However, not all chondrocytes benefit from hypoxia. Kean et al. showed that hypoxia, while beneficial for articular-derived chondro- genesis, is detrimental for auricular-derived chondrogenesis under the same conditions [43].

Gruenloh et al. found that hypoxic (3.0\% oxygen) treatment promoted in vitro migration of the human embryonic stem cell (hESC) line H9 (H9-MSCs), as demonstrated by significantly stronger cell mobility efficiency than that under normoxic conditions (5.0\% CO2/ambient O2) [44]. Boyette et al. found that hypoxic treatment ( $5 \%$ oxygen) of human SDSCs prevented senescence induction, evidenced by 2.70 fold-lower $(p<0.01)$ expression levels for P16 in low oxygen tension-tissue engineering cartilage (LOT-TEC). They also found that hypoxia promoted cellular proliferation and enhanced chondrogenic differentiation [40]. Meyer et al. showed through direct comparison that low oxygen conditions are a more potent prochondrogenic stimulus than dynamic compression [45]. In contrast, there have been reports of negative effects of severe hypoxia on proliferation and differentiation of bone marrow mesenchymal stem cells (BM-MSCs). This may be because the pO2 is so low that BM-MSCs have to slow down their differentiation through molecular mechanisms [46]. This is why we need to choose more accurate oxygen tension conditions in the bioreactor to simulate the intra-articular environment.

There is no doubt that oxygen concentration is a very important culture parameter. By controlling the oxygen production concentration in a bioreactor, the fate of cells can be controlled in the desired direction.

3.2. Mechanical Stimulation. Mechanical stimulation plays an important role in the gene expression of seed cells in bioreactors. Seeded cells in scaffolds are not able to achieve the same biomechanical and histological properties as natural AC tissue without mechanical stimulation. In this section, mechanical stimulation is classified into three types: hydrostatic pressure (HP), shear, and compressive forces (CFs) (Figure 2) according to the different stress ranges and directions of TEAC to mechanical load. Moreover, we summarize the mechanical transduction mechanism and the design of bioreactors applied by different mechanical stimuli in AC tissue engineering. Finally, some of the latest research progress is discussed.

3.2.1. Hydrostatic Pressure. Synovial fluid in the articular cavities of the knee joint and hip joint not only provides the necessary nutrients but also lubricates the joint surface. In the daily activities of humans, the surface tissues and cells of AC are subjected to fluid shear and HP in the liquid environment. Therefore, body fluids are an indispensable biomechanical condition in the construction of TEAC. Vunjak-Novakovic et al. suggested that the hydrodynamic conditions in bioreactors can enhance the secretion of GAG and collagen in the ECM of chondrocytes and regulate the morphology, mechanical, and electromechanical properties of tissue-engineered cartilage [47].

$\mathrm{HP}$ is the most common mechanical stimulation of the fluid environment. Endogenous AC bears intermittent HP, which is produced during human exercise. Tissues and cells are subjected to compression forces of uniform range and multiple directions under $\mathrm{HP}$. The range of $\mathrm{HP}$ in $\mathrm{AC}$ is 
TABLE 2: Summary of responses of seed cells to different design factors in bioreactors.

\begin{tabular}{|c|c|c|c|c|}
\hline Authors & Cell+scaffold type & $\begin{array}{l}\text { Design } \\
\text { condition }\end{array}$ & $\begin{array}{l}\text { Loading } \\
\text { parameters }\end{array}$ & Results \\
\hline Kean et al. [37] & $\begin{array}{l}\text { Human chondrocytes+porcine } \\
\text { devitalized synoviocyte matrix } \\
\text { scaffold }\end{array}$ & LOT & $5 \%$ & Promote chondrogenesis \\
\hline Shearier et al. [38] & hMSCs spheroids+scaffold-free & LOT & $\begin{array}{l}2 \% \\
4 \text { days }\end{array}$ & $\begin{array}{l}\text { Maintain stemness } \\
\text { Upregulate the synthesis of ECM } \\
\text { components and growth factors }\end{array}$ \\
\hline Shi et al. [39] & $\begin{array}{l}\text { Rat ASCs and chondrocytes } \\
\text { +scaffold-free }\end{array}$ & LOT & $\begin{array}{l}2 \% \\
3 \text { days }\end{array}$ & $\begin{array}{c}\text { Promote chondrogenic differentiation } \\
\text { Enhance proliferation }\end{array}$ \\
\hline Yasui et al. [40] & $\begin{array}{l}\text { Human synovial MSCs } \\
+ \text { +scaffold-free }\end{array}$ & LOT & $\begin{array}{c}5 \% \\
200 \text { days }\end{array}$ & $\begin{array}{c}\text { Prevent senescence } \\
\text { Promote chondrogenic differentiation } \\
\text { Enhance proliferation }\end{array}$ \\
\hline Hwang et al. [41] & Human ADSCs+scaffold-free & LOT & $\begin{array}{l}1 \% \\
2 \text { days }\end{array}$ & $\begin{array}{c}\text { Increase migration } \\
\text { Promote chondrogenic differentiation } \\
\text { Decrease osteogenic differentiation }\end{array}$ \\
\hline Cheng et al. [53] & $\begin{array}{l}\text { Rabbit BMSCs+PRF } \\
\text { membrane scaffold }\end{array}$ & HP & $\begin{array}{c}0.12 \mathrm{MPa} \\
1 \mathrm{~h} \\
4 \text { days }\end{array}$ & $\begin{array}{l}\text { Promote proliferation and chondrogenic } \\
\text { differentiation }\end{array}$ \\
\hline Shahmoradi et al. [54] & $\begin{array}{l}\text { hBMSCs+human } \\
\text { demineralized bone matrix } \\
\text { scaffold }\end{array}$ & Cyclic HP & $\begin{array}{c}5 \mathrm{MPa} \\
0.5 \mathrm{~Hz} \\
4 \mathrm{~h} \\
7 \text { days }\end{array}$ & Improve chondrogenic differentiation \\
\hline Hodder et al. [52] & $\begin{array}{l}\text { 3D cultured chondrocytes } \\
+ \text { +scaffold-free }\end{array}$ & Static HP & $\begin{array}{l}\leq 5-10 \mathrm{MPa} \\
\geq 14 \text { days }\end{array}$ & Improve generation of cartilage \\
\hline Nazempour et al. [59] & $\begin{array}{l}\text { Bovine chondrocytes+agarose } \\
\text { scaffold }\end{array}$ & $\begin{array}{l}\text { Oscillating } \\
\text { HP } \\
\text { Fluid shear }\end{array}$ & $\begin{array}{c}0.02 \mathrm{~Pa}, 21 \text { days } \\
\text { for shear } \\
0.5 \mathrm{~Hz}, 4 \mathrm{MPa} \text {, } \\
4 \mathrm{~h} / \text { day, } 15 \text { days } \\
\text { for OHP }\end{array}$ & $\begin{array}{l}\text { Protect cartilage } \\
\text { Enhance extracellular matrix synthesis }\end{array}$ \\
\hline Theodoropoulos et al. [60] & $\begin{array}{c}\text { Bovine chondrocytes+cylinders } \\
\text { of CPP scaffold }\end{array}$ & Tissue shear & $\begin{array}{l}90 \mathrm{rpm} \\
28 \text { days }\end{array}$ & Alter expression of integrin \\
\hline Grad et al. [61] & $\begin{array}{l}\text { Bovine chondrocytes } \\
\text { +polyurethane scaffold }\end{array}$ & Tissue shear & $\begin{array}{c}1 \mathrm{~Hz} \\
1 \mathrm{~h} \\
21 \text { days }\end{array}$ & $\begin{array}{c}\text { Regenerate and maintain functional joint } \\
\text { surface } \\
\text { Support mechanical capability }\end{array}$ \\
\hline Jonnalagadda et al. [62] & $\begin{array}{l}\text { Human articular chondrocytes } \\
\text { + scaffold-free }\end{array}$ & $\begin{array}{l}\text { Oscillating } \\
\text { shear }\end{array}$ & $\begin{array}{l}1-50 \mathrm{~Hz} \\
21 \text { days }\end{array}$ & Promote hyaline cartilage formation \\
\hline DiFederico et al. [71] & $\begin{array}{l}\text { Bovine chondrocytes+agarose } \\
\text { Scaffold }\end{array}$ & $\begin{array}{l}\text { Dynamic } \\
\text { compression }\end{array}$ & $\begin{array}{l}15 \% \text { strain } \\
1 \mathrm{~Hz} \\
2 \text { days }\end{array}$ & $\begin{array}{l}\text { Upregulate the synthesis of ECM } \\
\text { components }\end{array}$ \\
\hline Guo et al. [72] & $\begin{array}{l}\text { hMSCs encapsulated alginate } \\
\text { hydrogel beads+scaffold-free }\end{array}$ & $\begin{array}{l}\text { Dynamic } \\
\text { compression }\end{array}$ & $\begin{array}{l}0.5 \mathrm{~Hz} \\
0-6813 \mathrm{~Pa} \\
21 \text { days }\end{array}$ & $\begin{array}{l}\text { Upregulate the synthesis of ECM } \\
\text { components } \\
\text { Promote proliferation }\end{array}$ \\
\hline Wang et al. [73] & rBMSCs+CS/SF/n-HA scaffold & $\begin{array}{l}\text { Periodic } \\
\text { dynamic } \\
\text { compression }\end{array}$ & $\begin{array}{c}10 \% \text { strain } \\
0.5 \mathrm{~Hz} \\
2 \mathrm{~h} \text { action }+4 \mathrm{~h} \\
\text { pause/cycle, } 4 \\
\text { cycles/day } \\
14 \text { days }\end{array}$ & Increase compression modulus \\
\hline Gamez et al. [75] & pBM-MSCs+alginate scaffold & $\begin{array}{l}\text { Periodic } \\
\text { dynamic } \\
\text { compression }\end{array}$ & $\begin{array}{c}10 \% \text { strain } \\
0.3 \mathrm{~Hz} \\
180 \text { cycle } \\
\text { (10 mins) action } \\
+10 \text { s pause } \\
1 \text { day }\end{array}$ & Induce migration \\
\hline
\end{tabular}


TABLE 2: Continued.

\begin{tabular}{|c|c|c|c|c|}
\hline Authors & Cell+scaffold type & $\begin{array}{c}\text { Design } \\
\text { condition }\end{array}$ & $\begin{array}{c}\text { Loading } \\
\text { parameters }\end{array}$ & Results \\
\hline Chong et al. [77] & $\begin{array}{c}\text { Human osteoarthritic } \\
\text { chondrocytes+agarose scaffold }\end{array}$ & $\begin{array}{l}\text { Uniaxial } \\
\text { dynamic } \\
\text { compression }\end{array}$ & $\begin{array}{c}20 \% \text { strain } \\
1 \mathrm{~Hz} \\
\text { Sinusoidal } \\
\text { waveform } \\
8 \text { days }\end{array}$ & $\begin{array}{l}\text { Enhance biosynthetic activity of } \\
\text { osteoarthritic chondrocytes }\end{array}$ \\
\hline Ciombor et al. [80] & Chondrocytes+scaffold-free & PEMFs & $\begin{array}{l}\text { Low-frequency } \\
\text { EMF }\end{array}$ & Enhance the chondrogenic differentiation \\
\hline Wilmot et al. [81] & $\begin{array}{l}\text { The cartilage layer of rat joints } \\
+ \text { +scaffold-free }\end{array}$ & PEMFs & $\begin{array}{l}75 \mathrm{~Hz} \\
\text { PEMF }\end{array}$ & $\begin{array}{c}\text { Negative effect on the culture of cartilage } \\
\text { tissue }\end{array}$ \\
\hline Štolfa et al. [82] & $\begin{array}{l}\text { Human cartilage tissue } \\
\text { +scaffold-free }\end{array}$ & SMF & $\begin{array}{l}0.6 \mathrm{~T} \\
\mathrm{SMF}\end{array}$ & Increase metabolic activity \\
\hline Hsieh et al. [83] & $\begin{array}{l}\text { Human chondrocyte+scaffold- } \\
\text { free }\end{array}$ & SMF & $\begin{array}{l}3 \mathrm{~T} \\
\mathrm{SMF}\end{array}$ & $\begin{array}{l}\text { Reduce cell proliferation and induced cell } \\
\text { apoptosis }\end{array}$ \\
\hline Zhang et al. [88] & Chondrocytes+scaffold-free & LIUS & $1.5 \mathrm{MHz}$ & $\begin{array}{l}\text { Increase the expression of collagen II and } \\
\text { inhibit the development of chondrocyte } \\
\text { hypertrophy }\end{array}$ \\
\hline Hasanova et al. [89] & $\begin{array}{l}\text { Bovine chondrocytes+chitosan } \\
\text { Scaffold }\end{array}$ & LIUS & $5.0 \mathrm{MHz}$ & $\begin{array}{l}\text { Modulate the proliferation and } \\
\text { expression of specific genes }\end{array}$ \\
\hline
\end{tabular}

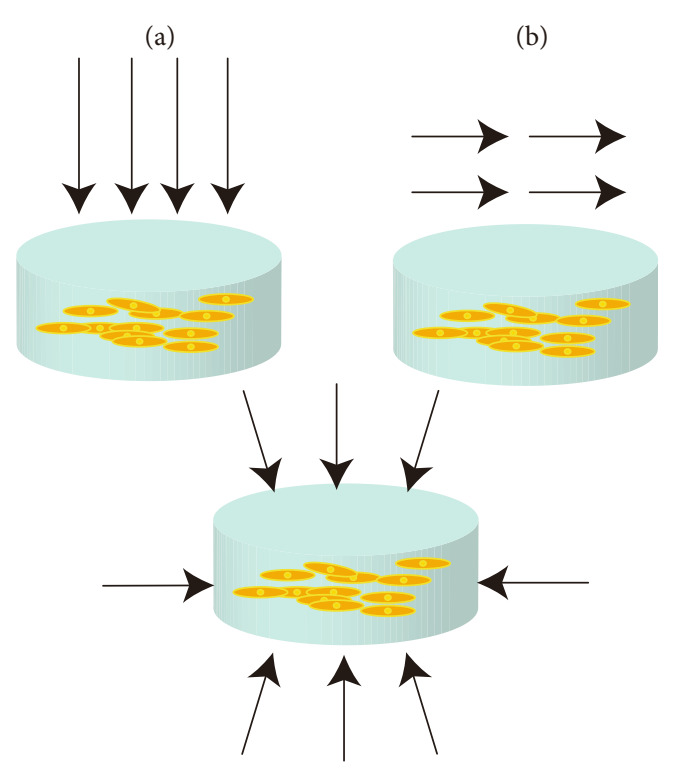

(c)

Figure 2: The arrows indicate the direction of the mechanical load acting on TEAC. (a) Compression. (b) Shear. (c) HP.

approximately 5-6 MPa upon walking and can reach $18 \mathrm{MPa}$ upon running and jumping [48]. In addition, the HP frequency accompanies the human walking rhythm, which is usually no more than $1 \mathrm{~Hz}$ [49]. Therefore, in the design of HP-related bioreactors, the range and frequency of HP should be controlled within the above normal physiological range as much as possible. Because HP essentially does not shear or deform tissue, the damage of HP to the ECM is minimal for all mechanical stimuli in the joint. In recent years, the study of HP has been a hot topic in the field of tissue engineering cartilage, where it is considered the most important mechanical load [50]. HP is increasingly being recognized by researchers as an effective method for the cultivation and stimulation of chondrocytes in monolayer, threedimensional (3-D) engineering structures, as well as in explants [51].

For the design of HP bioreactors, there are two main methods of applying HPs to cells: explants and constructs. In explants, HP transmits liquid pressure through the gas phase of the compressed medium. Since the oxygen tension in the pressurized medium changes as the gas phase is compressed, there are some limitations in the construction scheme of HP in the explants. The other method for constructs applies high pressure by compressing the liquid phase only, which prevents the solubility of oxygen in the medium from changing, as the pressure does not change during compression. This method cannot be used to examine the effect of HP on TEAC at different oxygen levels. The method for constructs usually involves connecting a fluid-filled chamber to a piston on a controllable hydraulic press through a hose [51]. These two different types of HP applications have their own advantages and disadvantages, and researchers can choose one or the other based on whether the HP experiment needs to be combined with changes in oxygen partial pressure.

Through meta-analysis, Hodder et al. concluded that static HP with a reaction time of more than 2 weeks in the physiological range of medium and high cartilage $(\leq 5$ $10 \mathrm{MPa}$ ) is an ideal condition for tissue-engineered cartilage to produce large amounts of proteoglycans [52]. In another study, Cheng et al. found that HP stimulation of $0.12 \mathrm{MPa}$ for $1 \mathrm{~h}$ /day for 4 days could significantly improve the function of BMSCs secreting cartilage matrix in rabbit $\mathrm{BMSC} / \mathrm{PRF}$ (platelet-rich fibrin) construct during the process of chondrocyte differentiation [53]. Similarly, cyclic HP $(0.5 \mathrm{~Hz}, 5 \mathrm{MPa}, 4 \mathrm{~h} /$ day for 1 week) was found to significantly improve the chondrogenic differentiation ability of hBMSCs 
in demineralized bone matrix scaffolds [54]. HP is a mechanical load that can be easily applied to the large-scale construction of engineered cartilage due to its uniform effect on cartilage tissue. However, mechanical stimulation of HP is insufficiently multiform to form normal physiological layered cartilage through this loading type alone. Existing HP bioreactors have preliminarily incorporated techniques regarding different HP conditions on cartilage formation and cartilage, and researchers may focus on the regulation of cellular behavior in HP research in the future. Further specific review of the role of hydrostatic forces in regulating cell behavior was provided by Liu et al. [55].

3.2.2. Shear. Shear is a load parallel to the AC surface generated by a liquid or solid medium during normal physiological activity. When cartilage tissue is compressed, there is a potential fluid shear force in and around the cell membrane during the discharge of large amounts of water. Then, with the compression force removed, the discharged water returns to its original position due to the osmotic pressure change and produces corresponding fluid shear stresses again [56, 57]. In addition, the proximal and distal sliding of the joint, such as the femoral condyle and tibial plateau in the knee joint, produces direct shear forces. Generally, it is suggested that continuous shear force is harmful to AC in vivo. The cartilage surface gradually wears away and degrades, and the possibility of inducing $\mathrm{OA}$ increases during the continuous application of shear force. Unlike the above, in the field of tissue engineering, shear stimulation has been used by researchers to improve TEAC structural properties in vitro. Past studies have shown that shear forces can increase cartilage matrix composition $[58,59]$, promote tensile properties [58], alter the expression of integrin [60], and reduce the friction coefficient under appropriate magnitude and frequency stimulation [61]. Oscillating shear is a common loading method in fluid and direct shear bioreactors, which can make TEAC have similar structure and mechanical properties as natural cartilage $[62,63]$. By searching and summarizing the research articles related to cartilage tissue engineering and computer modeling, Pearce et al. concluded that computational modeling can help better characterize the liquid shear stress of the bioreactor, improve the scaffold structure, and control the mechanical properties of tissue-engineered cartilage through further modeling the growth, development, and movement of cells [64].

Nazempour et al. designed a bioreactor system that combined shear stress and oscillating hydrostatic pressure (OHP). The results showed that the secretion of GAG and collagen by chondrocytes was significantly higher than that of static culture, and the effect was better when both mechanical stimuli were applied simultaneously. In addition, low expression levels of -1 integrin and type- $\mathrm{X}$ collagen genes were found. The shear force and OHP may have protective effects on the cartilage due to the increase in the elastic modulus measured by atomic force microscopy under the combined load [59]. The shear load is applied only in the direction parallel to the chondral surface, corresponding to the formation of a horizontal AC surface; thus, there is a significant deficiency in the construction of TEAC using shear force alone as a mechanical stimulus aid. To produce highquality engineered cartilage, additional mechanical loads must be superimposed. In recent years, most of the improved bioreactors have been designed for multiaxial loading, providing new insights into the responses of chondrocytes and chondrogenic stem cells to specific types of loading (especially shear).

For the design of shear bioreactors, according to the properties of mediators required for the transmission of shear load at the cartilage tissue level, shear has been divided into fluid-induced shear and tissue shear. Fluid shear bioreactors simulate the load on cells and tissues during the flow of synovial fluid and intercellular fluid in the body. Agitation systems in liquid environments, such as rotating flasks and direct perfusion systems, apply high shear forces, while RWVs apply low shear forces [65]. Bonnevie et al. found that high shear forces were closely associated with mitochondrial dysfunction, apoptosis, and cell death [66]. The mechanical stress in a low-shear bioreactor is usually less than $0.1 \mathrm{~Pa}$, which was proven to increase extracellular matrix content and cartilage formation without damaging cells [58,67]. Shear force between tissues usually occurs synchronously with compression force during normal physiological activities. Schätti et al. designed a bioreactor that utilizes a combination of shear and dynamic compression. The results showed that compression or shear alone cannot induce human BM-MSCs to differentiate into cartilage. The shear superimposed on the dynamic compression combination resulted in a significant increase in chondrogenic gene expression. Increases in sGAG and collagen were detected in only the mechanical combination group [68].

3.2.3. Compressional Forces. AC, as a mechanoactive tissue, undergoes compression on a daily basis. In the processes of human movement, under the action of compression force, the relative collision of two articular surfaces in the joint causes deformation of the cartilage tissue. The magnitude, frequency, and profile of the pressure are important parameters of pressure load in bioreactor research. The average pressure of $\mathrm{AC}$ as the load-bearing tissue of the knee joint is approximately 0.5-7.7 MPa. Under physiological compression, the average shape variable of $\mathrm{AC}$ can be up to approximately $1 / 8$ of its thickness $[69,70]$. Cartilage tissue includes specific chondrocyte sequences and extracellular matrix components for physiological compression. At present, most of the research on mechanical stimulation and bioreactors is related to compression force. Studies have shown that compression is beneficial for chondrocytes to upregulate the synthesis of ECM components [71, 72], promote the proliferation of stem cells [72], and increase the compression modulus of cells/scaffolds [73]. Other studies have pointed out that mechanical stimulation can induce the migration of stem cells and chondrocytes under the condition of intermittent compression [74, 75]. Anderson et al. searched the PubMed database to identify relevant publications up to 2017 and found that there is little standardization of research work in the field of dynamic stress-induced chondrogenesis. In most of the studies searched, dynamic loading was found to have positive effects on chondrogenic gene 
expression, biomechanical modulus, and proteoglycan content, in contrast to its effect on collagen content [76]. Chong et al. found that $20 \%$ compression can enhance the biosynthetic activity of human chondrocytes from osteoarthritic joints, which suggests that dynamic compression is equally effective as static compression for the biosynthesis of chondrocytes from osteoarthritis [77].

For the design of compression bioreactors, the reactor provides a controlled environment for assessing the impact of cartilage compression. For compression load bioreactor design, it is necessary to determine the compression state (dynamic or static compression) as well as its strain amplitude, duration, and frequency. By changing the strain and duration, Chen et al. determined that the optimal dynamic culture conditions of chondrocytes in refrigerated gel scaffolds under a cyclic dynamic compression load of $1 \mathrm{~Hz}$ were as follows: $20 \%$ strain and $3 \mathrm{~h} / \mathrm{d}$ stimulation time. In addition, the feasibility and effectiveness of mechanical stimulation to promote chondrogenic differentiation of ASCs through coculture of chondrocytes and ASCs in vitro were confirmed [78].

\subsection{Noncontact Physical Stimulation}

3.3.1. Electromagnetic Field (EMF) Stimulation. Electromagnetic fields (EMFs) are another extrinsic factor in the culture of cells and tissues. Due to the piezoelectricity of hyaline cartilage's extracellular matrix, natural articular cartilage can convert electromagnetic oscillations into mechanical oscillations and vice versa [79]. As mentioned above, recent studies have found that EMFs can affect chondrocyte proliferation and articular chondrocyte extracellular matrix formation [29, 79]. Based on how magnetic fields change over time, EMFs can be divided into static magnetic fields (SMFs) and pulsed EMFs (PEMFs). An SMF has a constant magnetic field, while PEMFs have a certain pulse frequency. Ciombor et al. used the demineralized bone matrix- (DBM-) induced endochondral ossification model to show the effects of PEMFs stimulation. The results show that low-frequency EMF can enhance the chondrogenic differentiation in an endochondral ossification model [80]. To the contrary, Wilmot et al. exposed the cartilage layer of rat joints to PMEF with a frequency of $75 \mathrm{~Hz}$. The results showed that the electromagnetic field had a negative effect on the culture of cartilage tissue [81]. In addition to frequency, the strength of the electromagnetic field is also an important parameter. Stolfa et al. found that a $0.6 \mathrm{~T}$ static magnetic field (SMF) increased metabolic activity in human cartilage tissue [82], whereas Hsieh et al. determined that a high-intensity SMF [3 Tesla (T)] reduced human chondrocyte cell proliferation and induced cell apoptosis [83]. In addition, many studies have shown that the moderate-intensity SMFs ( $1 \mathrm{mT}$ to $1 \mathrm{~T}$ ) can increase the proliferation of cells $[84,85]$. For example, Jaberi et al. studied the effects of a moderateintensity permanent magnetic field $(40 \mathrm{mT})$ on cartilage repair in an animal model. The result showed that a moderateintensity SMF $(40 \mathrm{mT})$ enhanced the repair of cartilage damage in rabbits [30].

In brief, for the design of magnetic bioreactors, it is vital to determine the type, intensity, and frequency of electro- magnetic fields promoting the behavior of cells in a favorable direction.

3.3.2. Ultrasonic Stimulation. With the wide application of ultrasound (US) in the industrial and biomedical fields, its interaction with living cells and tissues has been extensively studied. The regulation of cells by US is bidirectional, and in vitro studies have shown that high-intensity US can induce cell death through lysis, necrosis, or apoptosis [86, 87]. Therefore, we need to consider many factors when using US, such as the prediction of cell death model and control of US intensity, to obtain the biological effects we need to the maximum extent and minimize the adverse effects. Recent studies have shown that low-intensity continuous ultrasound (LIUS) has critical effects on cartilage metabolism, cartilage repair, and the culture of chondrocytes and mesenchymal stem cells (MSCs). For example, Zhang et al. studied the effects of pulsed LIUS $(1.5 \mathrm{MHz})$ on chondrocyte culture. The results showed that the LIUS increased the expression of collagen II and inhibited the development of chondrocyte hypertrophy [88].

LIUS is also being widely applied in AC tissue engineering combined with the 3D culture of chondrocytes and MSCs. For instance, Hasanova et al. used low-intensity diffuse ultrasound $\left(5.0 \mathrm{MHz}, 0.14 \mathrm{~mW} / \mathrm{cm}^{2}\right)$ to stimulate bovine chondrocytes seeded in three-dimensional (3D) chitosanbased scaffolds and evaluated the expression levels of chondrocyte-specific genes. In conclusion, it suggested that US stimulation can modulate the proliferation and expression of specific genes of chondrocytes seeded in 3D matrices [89]. Therefore, based on the positive bioeffects of LIDUS and their applications to the field of cartilage tissue engineering, we can design and develop an ideal ultrasonic bioreactor.

LOT: low oxygen tension; HP: hydrostatic pressure; hMSCs: human mesenchymal stromal cells; hBMSCs: human bone marrow mesenchymal stromal cells; ASCs: adipose-derived stromal cells; PRF: platelet-rich fibrin; CPP: calcium polyphosphate; rBMSCs: rat bone marrow stromal cells; CS: chitosan; SF: silk fibrin; n-HA: nano-hydroxyapatite; pBM-MSCs: porcine bone marrow-derived mesenchymal stem/stromal cells; PEMFs: pulsed electromagnetic fields; SMF: static magnetic field; LIUS: low-intensity continuous ultrasound.

\section{Application of Existing Bioreactors in Combination with Other Emerging Technologies}

4.1. 3D-Printed (3DP) Bioreactors. Current bioreactor systems face problems of limited customization capability, high cost, and lack of force measurement capability. It seems feasible to design and manufacture a low-cost custom bioreactor system using 3D printing technology. We can use 3D printing technology to build a culture chamber, maintain cells and engineered tissue in the medium, and place TEAC using custom grips.

Abigail et al. developed a 3DP stretch bioreactor with potential applications for multiple tissues. The group developed custom software to independently control three actuators and monitor the weighing elements for high-throughput 
loading experiments and to evaluate the mechanical properties of the organization under development. The results of this in vitro study and mechanical evaluation indicated that 3DP technology is a viable platform for the development of customizable, low-cost, and multifunctional mechanical bioreactor systems [90].

4.2. Bioreactors Using Microcarriers. One limitation of traditional flask or multilayer cell culture is its low surface to volume ratio, which often leads to an insufficient number of available cells. However, in the field of tissue-engineered cartilage regeneration, there are some seed cells, such as synovial-derived mesenchymal stem cells (SF-MSCs) [91], which are lacking in organization. Their specific chondrogenic differentiation potential is also important for cartilage regeneration [92]. Therefore, it is necessary to proliferate in the coculture system to produce experimentally and clinically usable numbers of MSCs. Van Wezel introduced the microcarrier culture system in 1967 [93]. The combination of a bioreactor with a microcarrier can improve cell proliferation while reducing time, cost, and manual operation and significantly improve relative repeatability. Microcarriers can enhance cell adhesion and suspend cells in the culture system, which greatly increases the number of cultured cells $[91,94]$. As early as 1997, Baker et al. cocultured bovine chondrocytes and Cytodex-3 microcarriers in an RWV. This experiment showed that the three-dimensional environment of the coculture system played a role in the growth, differentiation, and ECM formation of bovine chondrocytes [95]. Another advantage of the microcarrier is that the cellimplanted microcarrier can be transferred directly to the site of repair, avoiding the steps of collecting cells and planting them on the scaffold [96]. Lam et al. reported that biodegradable poly (epsilon-caprolactone) microcarriers combining bioreactors greatly increased the production of hMSCs and cell secretion factors [97].

Bioreactor and microcarrier coculture systems can not only reduce costs but also promote more efficient liquid oxygen exchange and maintenance of the extracellular environment. In addition, the system can regulate the oxygen partial pressure and $\mathrm{pH}$ of the cell environment acting on the mechanical loading of the cell. Therefore, the system can effectively manage and regulate tissue-engineered cells.

\section{Conclusion and Future Perspectives}

Bioreactors have been used to improve the quality of cartilage tissue engineering by importing physiological environmental factors present in natural $\mathrm{AC}$, such as oxygen and $\mathrm{pH}$, nutrient delivery, and mechanical loading. The potential of bioreactors in tissue engineering is clear, although the role of stimulation by various mechanical loads in directing cellular behavior is controversial. In addition, various new technologies and strategies have been applied in combination with bioreactors, not only greatly improving the efficiency of the bioreactor but also ultimately enabling the construction and culture of high-quality tissue-engineered cartilage.

Despite this, further investigation is needed to elucidate the specific biochemical and biomechanical factors required for the development of cells, tissues, or organs. Results and parameters of theoretical research are indispensable for the design of bioreactors, which is beneficial to fully understand the regulatory mechanisms of cartilage growth and differentiation in order to produce successfully engineered tissues with the best characteristics. Most importantly, the basic mechanical biology should also be explored to enhance this achievement. In addition, there are also some new ideas for bioreactors, such as the proposal of the in vivo bioreactor, which provides a promising approach to provide in vivo conditions for cartilage engineering. Finally, the combination of tissue engineering and advanced technologies is not only the development trend of tissue engineering but also the development direction of bioreactors. We believe that the application of bioreactors in cartilage tissue engineering, especially the customized construction of in vitro engineered cartilage, will play a significant role in the personalized treatment and prognosis of clinical cartilage damage repair in the future.

\section{Conflicts of Interest}

The authors declare that they have no competing interests.

\section{Authors' Contributions}

FLW and LPX designed the manuscript and wrote sections of it. LH wrote part of the manuscript with insights from all other authors. YZ and GCJ conceptualized and generated Tables 1 and 2. Zhao Tianyuan, Chen Wei, Liao Zhiyao, Peng $\mathrm{Yu}$, and Cao Fuyang conceptualized and generated Figures 1 and 2. Sui Xiang, Liu Shuyun, and Guo Quanyi revised and finalized the manuscript. All authors read and approved the final manuscript. Fu Liwei and Li Pinxue contributed equally to this work and were co-first authors.

\section{Acknowledgments}

This work was supported by the National Key Research and Development Program of China (No. 2019YFA0110600) and the National Natural Science Foundation of China (No. 81772319).

\section{References}

[1] Z. Yang, H. Li, Z. Yuan et al., "Endogenous cell recruitment strategy for articular cartilage regeneration," Acta Biomaterialia, vol. 114, pp. 31-52, 2020.

[2] C. Deng, C. Xu, Q. Zhou, and Y. Cheng, "Advances of nanotechnology in osteochondral regeneration," Wiley Interdisciplinary Reviews Nanomedicine and Nanobiotechnology, vol. 11, no. 6, article e1576, 2019.

[3] I. Gadjanski, "Mimetic Hierarchical Approaches for Osteochondral Tissue Engineering," in Osteochondral Tissue Engineering. Advances in Experimental Medicine and Biology, vol 1058, J. Oliveira, S. Pina, R. Reis, and J. San Roman, Eds., Springer, Cham, 2018.

[4] A. Di Luca, C. Van Blitterswijk, and L. Moroni, "The osteochondral interface as a gradient tissue: from development to the fabrication of gradient scaffolds for regenerative 
medicine," Birth Defects Research Part C, Embryo Today, vol. 105, no. 1, pp. 34-52, 2015.

[5] Z. Qiao, M. Lian, Y. Han et al., "Bioinspired stratified electrowritten fiber-reinforced hydrogel constructs with layer-specific induction capacity for functional osteochondral regeneration," Biomaterials, vol. 266, article 120385, 2020.

[6] W. Wei, Y. Ma, X. Yao et al., "Advanced hydrogels for the repair of cartilage defects and regeneration," Bioactive Materials, vol. 6, no. 4, pp. 998-1011, 2021.

[7] G.-i. Im and T.-K. Kim, "Overcoming current dilemma in cartilage regeneration: will direct conversion provide a breakthrough?," Tissue Engineering and Regenerative Medicine, vol. 17, no. 6, pp. 829-834, 2020.

[8] S. Jiang, W. Guo, G. Tian et al., "Clinical application status of articular cartilage regeneration techniques: tissue-engineered cartilage brings new hope," Stem Cells International, vol. 2020, Article ID 5690252, 16 pages, 2020.

[9] L. Chen, J. Liu, M. Guan, T. Zhou, X. Duan, and Z. Xiang, "Growth factor and its polymer scaffold-based delivery system for cartilage tissue engineering," International Journal of Nanomedicine, vol. 15, pp. 6097-6111, 2020.

[10] I. M. Zurina, V. S. Presniakova, D. V. Butnaru, A. A. Svistunov, P. S. Timashev, and Y. A. Rochev, "Tissue engineering using a combined cell sheet technology and scaffolding approach," Acta Biomaterialia, vol. 113, pp. 63-83, 2020.

[11] Y. Han, X. Li, Y. Zhang, Y. Han, F. Chang, and J. Ding, "Mesenchymal stem cells for regenerative medicine," Cell, vol. 8, no. 8, 2019.

[12] H. Le, W. Xu, X. Zhuang, F. Chang, Y. Wang, and J. Ding, "Mesenchymal stem cells for cartilage regeneration," Journal of Tissue Engineering, vol. 11, Article ID 2041731420943839, 2020.

[13] G. Chen and N. Kawazoe, "Porous scaffolds for regeneration of cartilage, bone and osteochondral tissue," Osteochondral Tissue Engineering, vol. 1058, pp. 171-191, 2018.

[14] C. H. Evans, "Native, living tissues as cell seeded scaffolds," Annals of Biomedical Engineering, vol. 43, no. 3, pp. 787-795, 2015.

[15] L. Fu, Z. Yang, C. Gao et al., "Advances and prospects in biomimetic multilayered scaffolds for articular cartilage regeneration," Regenerative Biomaterials, vol. 7, no. 6, pp. 527-542, 2020.

[16] P. S. Couto, M. C. Rotondi, A. Bersenev et al., "Expansion of human mesenchymal stem/stromal cells (hMSCs) in bioreactors using microcarriers: lessons learnt and what the future holds," Biotechnology Advances, vol. 45, article 107636, 2020.

[17] N. Sharifi and A. M. Gharravi, "Shear bioreactors stimulating chondrocyte regeneration, a systematic review," Inflammation and Regeneration, vol. 39, no. 1, p. 16, 2019.

[18] E. Y. Salinas, J. C. Hu, and K. Athanasiou, “A guide for using mechanical stimulation to enhance tissue-engineered articular cartilage properties," Tissue Engineering Part B: Reviews, vol. 24, no. 5, pp. 345-358, 2018.

[19] N. Mabvuure, S. Hindocha, and W. S. Khan, "The role of bioreactors in cartilage tissue engineering," Current Stem Cell Research \& Therapy, vol. 7, no. 4, pp. 287-292, 2012.

[20] S. Concaro, F. Gustavson, and P. Gatenholm, "Bioreactors for tissue engineering of cartilage," in Bioreactor Systems for Tissue Engineering. Advances in Biochemical Engineering/Biotechnology, vol 112, C. Kasper, M. Griensven, and R. Pörtner, Eds., Springer, Berlin, Heidelberg, 2008.
[21] D. A. Gaspar, V. Gomide, and F. J. Monteiro, "The role of perfusion bioreactors in bone tissue engineering," Biomatter, vol. 2, no. 4, pp. 167-175, 2012.

[22] J. Rauh, F. Milan, K.-P. Günther, and M. Stiehler, "Bioreactor systems for bone tissue engineering," Tissue Engineering Part B: Reviews, vol. 17, no. 4, pp. 263-280, 2011.

[23] F. Xu, L. Xu, Q. Wang, Z. Ye, Y. Zhou, and W. S. Tan, “3D dynamic culture of rabbit articular chondrocytes encapsulated in alginate gel beads using spinner flasks for cartilage tissue regeneration," BioMed Research International, vol. 2014, Article ID 539789, 10 pages, 2014.

[24] H. H. Yoon, S. H. Bhang, J. Y. Shin, J. Shin, and B. S. Kim, "Enhanced cartilage formation via three-dimensional cell engineering of human adipose-derived stem cells," Tissue Engineering Part A, vol. 18, no. 19-20, pp. 1949-1956, 2012.

[25] Y. Zhu, K. Song, S. Jiang et al., "Numerical simulation of mass transfer and three-dimensional fabrication of tissueengineered cartilages based on chitosan/gelatin hybrid hydrogel scaffold in a rotating bioreactor," Applied Biochemistry and Biotechnology, vol. 181, no. 1, pp. 250-266, 2017.

[26] R. C. Nordberg, L. F. Mellor, A. R. Krause, H. J. Donahue, and E. G. Loboa, "LRP receptors in chondrocytes are modulated by simulated microgravity and cyclic hydrostatic pressure," PLoS One, vol. 14, no. 10, article e0223245, 2019.

[27] K. Theodoridis, E. Aggelidou, M. Manthou, E. Demiri, A. Bakopoulou, and A. Kritis, "Assessment of cartilage regeneration on 3D collagen-polycaprolactone scaffolds: evaluation of growth media in static and in perfusion bioreactor dynamic culture," Colloids and Surfaces B, Biointerfaces, vol. 183, article 110403, 2019.

[28] S. Pigeot, P. E. Bourgine, J. Claude et al., "Orthotopic bone formation by streamlined engineering and devitalization of human hypertrophic cartilage," International Journal of Molecular Sciences, vol. 21, no. 19, p. 7233, 2020.

[29] M. De Mattei, A. Pellati, M. Pasello et al., "Effects of physical stimulation with electromagnetic field and insulin growth factor-I treatment on proteoglycan synthesis of bovine articular cartilage," Osteoarthritis and Cartilage, vol. 12, no. 10, pp. 793-800, 2004.

[30] F. M. Jaberi, S. Keshtgar, A. Tavakkoli et al., "A moderateintensity static magnetic field enhances repair of cartilage damage in rabbits," Archives of Medical Research, vol. 42, no. 4, pp. 268-273, 2011.

[31] A. D. Dikina, B. P. Lai, M. Cao, M. Zborowski, and E. Alsberg, "Magnetic field application or mechanical stimulation via magnetic microparticles does not enhance chondrogenesis in mesenchymal stem cell sheets," Biomaterials Science, vol. 5, no. 7, pp. 1241-1245, 2017.

[32] M. A. Brady, R. Vaze, H. D. Amin, D. R. Overby, and C. R. Ethier, "The design and development of a high-throughput magneto-mechanostimulation device for cartilage tissue engineering," Tissue Engineering Part C, Methods, vol. 20, no. 2, pp. 149-159, 2014.

[33] J. Dobson, S. H. Cartmell, A. Keramane, and A. J. El Haj, "Principles and design of a novel magnetic force mechanical conditioning bioreactor for tissue engineering, stem cell conditioning, and dynamic in vitro screening," IEEE Transactions on Nanobioscience, vol. 5, no. 3, pp. 173-177, 2006.

[34] S. Guha Thakurta, M. Kraft, H. J. Viljoen, and A. Subramanian, "Enhanced depth-independent chondrocyte proliferation and phenotype maintenance in an ultrasound bioreactor and an assessment of ultrasound dampening in 
the scaffold," Acta Biomaterialia, vol. 10, no. 11, pp. 47984810, 2014.

[35] N. P. Whitney, A. C. Lamb, T. M. Louw, and A. Subramanian, "Integrin-mediated mechanotransduction pathway of lowintensity continuous ultrasound in human chondrocytes," Ultrasound in Medicine \& Biology, vol. 38, no. 10, pp. 17341743, 2012.

[36] A. Subramanian, J. A. Turner, G. Budhiraja, S. Guha Thakurta, N. P. Whitney, and S. S. Nudurupati, "Ultrasonic bioreactor as a platform for studying cellular response," Tissue Engineering Part C, Methods, vol. 19, no. 3, pp. 244-255, 2013.

[37] T. J. Kean and J. E. Dennis, "Synoviocyte derived-extracellular matrix enhances human articular chondrocyte proliferation and maintains re-differentiation capacity at both low and atmospheric oxygen tensions," PLoS One, vol. 10, no. 6, article e0129961, 2015.

[38] E. Shearier, Q. Xing, Z. Qian, and F. Zhao, "Physiologically low oxygen enhances biomolecule production and stemness of mesenchymal stem cell spheroids," Tissue Engineering Part C, Methods, vol. 22, no. 4, pp. 360-369, 2016.

[39] S. Shi, J. Xie, J. Zhong et al., "Effects of low oxygen tension on gene profile of soluble growth factors in co-cultured adiposederived stromal cells and chondrocytes," Cell Proliferation, vol. 49, no. 3, pp. 341-351, 2016.

[40] Y. Yasui, R. Chijimatsu, D. A. Hart et al., "Preparation of scaffold-free tissue-engineered constructs derived from human synovial mesenchymal stem cells under low oxygen tension enhances their chondrogenic differentiation capacity," Tissue Engineering Part A, vol. 22, no. 5-6, pp. 490-500, 2016.

[41] O. K. Hwang, Y. W. Noh, J. T. Hong, and J. W. Lee, "Hypoxia pretreatment promotes chondrocyte differentiation of human adipose-derived stem cells via vascular endothelial growth factor," Tissue Engineering and Regenerative Medicine, vol. 17, no. 3, pp. 335-350, 2020.

[42] C. Merceron, C. Vinatier, S. Portron et al., "Differential effects of hypoxia on osteochondrogenic potential of human adiposederived stem cells," American Journal of Physiology Cell Physiology, vol. 298, no. 2, pp. C355-C364, 2010.

[43] T. J. Kean, H. Mera, G. A. Whitney et al., "Disparate response of articular- and auricular-derived chondrocytes to oxygen tension," Connective Tissue Research, vol. 57, no. 4, pp. 319333, 2016.

[44] W. Gruenloh, A. Kambal, C. Sondergaard et al., "Characterization and in vivo testing of mesenchymal stem cells derived from human embryonic stem cells," Tissue Engineering Part A, vol. 17, no. 11-12, pp. 1517-1525, 2011.

[45] E. G. Meyer, C. T. Buckley, S. D. Thorpe, and D. J. Kelly, "Low oxygen tension is a more potent promoter of chondrogenic differentiation than dynamic compression," Journal of Biomechanics, vol. 43, no. 13, pp. 2516-2523, 2010.

[46] C. Cicione, E. Muinos-Lopez, T. Hermida-Gomez, I. FuentesBoquete, S. Diaz-Prado, and F. J. Blanco, "Effects of severe hypoxia on bone marrow mesenchymal stem cells differentiation potential," Stem Cells International, vol. 2013, Article ID 232896, 11 pages, 2013.

[47] G. Vunjak-Novakovic, I. Martin, B. Obradovic et al., "Bioreactor cultivation conditions modulate the composition and mechanical properties of tissue-engineered cartilage," Journal of Orthopaedic Research, vol. 17, no. 1, pp. 130-138, 1999.

[48] P. D. Rushfeldt, R. W. Mann, and W. H. Harris, "Improved techniques for measuring_in vitro_the geometry and pressure distribution in the human acetabulum -II. Instrumented endoprosthesis measurement of articular surface pressure distribution," Journal of Biomechanics, vol. 14, no. 5, pp. 315-323, 1981.

[49] R. L. Waters, B. R. Lunsford, J. Perry, and R. Byrd, "Energyspeed relationship of walking: standard tables," Journal of Orthopaedic Research, vol. 6, no. 2, pp. 215-222, 1988.

[50] R. M. Schulz and A. Bader, "Cartilage tissue engineering and bioreactor systems for the cultivation and stimulation of chondrocytes," European Biophysics Journal, vol. 36, no. 4-5, pp. 539-568, 2007.

[51] B. D. Elder and K. A. Athanasiou, "Hydrostatic pressure in articular cartilage tissue engineering: from chondrocytes to tissue regeneration," Tissue Engineering Part B Reviews, vol. 15, no. 1, pp. 43-53, 2009.

[52] E. Hodder, F. Guppy, D. Covill, and P. Bush, "The effect of hydrostatic pressure on proteoglycan production in articular cartilage in vitro: a meta-analysis," Osteoarthritis and Cartilage, vol. 28, no. 8, pp. 1007-1019, 2020.

[53] B. Cheng, T. Tu, X. Shi et al., "A novel construct with biomechanical flexibility for articular cartilage regeneration," Stem Cell Research \& Therapy, vol. 10, no. 1, p. 298, 2019.

[54] S. R. Shahmoradi, M. Kabir Salmani, H. R. Soleimanpour et al., "Induction of chondrogenic differentiation in human mesenchymal stem cells cultured on human demineralized bone matrix scaffold under hydrostatic pressure," Tissue Engineering and Regenerative Medicine, vol. 16, no. 1, pp. 69-80, 2019.

[55] S. Liu, R. Tao, M. Wang et al., "Regulation of cell behavior by hydrostatic pressure," Applied Mechanics Reviews, vol. 71, no. 4, pp. 0408031-4080313, 2019.

[56] R. L. Smith, M. C. D. Trindade, T. Ikenoue et al., Effects of shear stress on articular chondrocyte metabolism, IOS Press, 2000.

[57] R. Lane Smith, B. S. Donlon, M. K. Gupta et al., "Effects of Fluid-Induced Shear on Articular Chondrocyte Morphology and Metabolism In Vitro," vol. 13, Tech. Rep. 6, Journal of Orthopaedic Research, 1995.

[58] C. V. Gemmiti and R. E. Guldberg, "Shear stress magnitude and duration modulates matrix composition and tensile mechanical properties in engineered cartilaginous tissue," Biotechnology and Bioengineering, vol. 104, no. 4, pp. 809-820, 2009.

[59] A. Nazempour, C. R. Quisenberry, N. I. Abu-Lail, and B. J. Van Wie, "Combined effects of oscillating hydrostatic pressure, perfusion and encapsulation in a novel bioreactor for enhancing extracellular matrix synthesis by bovine chondrocytes," Cell and Tissue Research, vol. 370, no. 1, pp. 179-193, 2017.

[60] J. S. Theodoropoulos, A. J. DeCroos, M. Petrera, S. Park, and R. A. Kandel, "Mechanical stimulation enhances integration in an in vitro model of cartilage repair," Knee Surgery, Sports Traumatology, Arthroscopy, vol. 24, pp. 2055-2064, 2016.

[61] S. Grad, M. Loparic, R. Peter, M. Stolz, U. Aebi, and M. Alini, "Sliding motion modulates stiffness and friction coefficient at the surface of tissue engineered cartilage," Osteoarthritis and Cartilage, vol. 20, no. 4, pp. 288-295, 2012.

[62] U. S. Jonnalagadda, M. Hill, W. Messaoudi et al., "Acoustically modulated biomechanical stimulation for human cartilage tissue engineering," Lab on a Chip, vol. 18, no. 3, pp. 473-485, 2018.

[63] N. Yusoff, N. A. Abu Osman, and B. Pingguan-Murphy, "Design and validation of a bi-axial loading bioreactor for 
mechanical stimulation of engineered cartilage," Medical Engineering \& Physics, vol. 33, no. 6, pp. 782-788, 2011.

[64] D. Pearce, S. Fischer, F. Huda, and A. Vahdati, "Applications of computer modeling and simulation in cartilage tissue engineering," Tissue Engineering and Regenerative Medicine, vol. 17, no. 1, pp. 1-13, 2020.

[65] R. Pörtner, C. Goepfert, K. Wiegandt et al., “Technical Strategies to Improve Tissue Engineering of Cartilage-Carrier-Constructs," in Bioreactor Systems for Tissue Engineering. Advances in Biochemical Engineering/Biotechnology, vol 112, C. Kasper, M. Griensven, and R. Pörtner, Eds., Springer, Berlin, Heidelberg, 2008.

[66] E. D. Bonnevie, M. L. Delco, L. R. Bartell et al., "Microscale frictional strains determine chondrocyte fate in loaded cartilage," Journal of Biomechanics, vol. 74, pp. 72-78, 2018.

[67] L. M. Kock, K. Ito, and C. C. van Donkelaar, "Sliding indentation enhances collagen content and depth-dependent matrix distribution in tissue-engineered cartilage constructs," Tissue Engineering Part A, vol. 19, no. 17-18, pp. 1949-1959, 2013.

[68] O. Schatti, S. Grad, J. Goldhahn et al., "A combination of shear and dynamic compression leads to mechanically induced chondrogenesis of human mesenchymal stem cells," European Cells \& Materials, vol. 22, pp. 214-225, 2011.

[69] S. Grad, D. Eglin, M. Alini, and M. J. Stoddart, "Physical stimulation of chondrogenic cells in vitro: a review," Clinical Orthopaedics and Related Research, vol. 469, no. 10, pp. 2764-2772, 2011.

[70] N. Y. P. Afoke, P. D. Byers, and W. C. Hutton, "Contact pressures in the human hip joint," The Journal of Bone and Joint Surgery British volume, vol. 69, pp. 536-541, 1987.

[71] E. DiFederico, J. C. Shelton, and D. L. Bader, "Complex mechanical conditioning of cell-seeded agarose constructs can influence chondrocyte biosynthetic activity," Biotechnology and Bioengineering, vol. 114, no. 7, pp. 1614-1625, 2017.

[72] T. Guo, L. Yu, C. G. Lim et al., "Effect of dynamic culture and periodic compression on human mesenchymal stem cell proliferation and chondrogenesis," Annals of Biomedical Engineering, vol. 44, no. 7, pp. 2103-2113, 2016.

[73] W. Wang, Y. Wan, T. Fu et al., "Effect of cyclic compression on bone marrow mesenchymal stromal cells in tissue engineered cartilage scaffold," Journal of Biomedical Materials Research Part A, vol. 107, no. 6, pp. 1294-1302, 2019.

[74] J. Nachtsheim, G. Dursun, B. Markert, and M. Stoffel, "Chondrocyte colonisation of a tissue-engineered cartilage substitute under a mechanical stimulus," Medical Engineering \& Physics, vol. 74, pp. 58-64, 2019.

[75] C. Gamez, B. Schneider-Wald, A. Schuette et al., "Bioreactor for mobilization of mesenchymal stem/stromal cells into scaffolds under mechanical stimulation: preliminary results," PLoS One, vol. 15, no. 1, article e0227553, 2020.

[76] D. E. Anderson and B. Johnstone, "Dynamic mechanical compression of chondrocytes for tissue engineering: a critical review," Frontiers in Bioengineering and Biotechnology, vol. 5, p. 76, 2017.

[77] P. P. Chong, P. Panjavarnam, W. Ahmad et al., "Mechanical compression controls the biosynthesis of human osteoarthritic chondrocytes in vitro," Clinical Biomechanics, vol. 79, article 105178, 2020.

[78] C. H. Chen, C. Y. Kuo, and J. P. Chen, "Effect of cyclic dynamic compressive loading on chondrocytes and adipose-derived stem cells co-cultured in highly elastic cryogel scaffolds," Inter- national Journal of Molecular Sciences, vol. 19, no. 2, p. 370, 2018.

[79] J. I. Jacobson, R. Gorman, W. S. Yamanashi, B. B. Saxena, and L. Clayton, "Low-amplitude, extremely low frequency magnetic fields for the treatment of osteoarthritic knees: a double-blind clinical study," Alternative Therapies in Health and Medicine, vol. 7, no. 5, pp. 54-64, 2001, 66-9.

[80] D. M. Ciombor, G. Lester, R. K. Aaron, P. Neame, and B. Caterson, "Low frequency EMF regulates chondrocyte differentiation and expression of matrix proteins," Journal of Orthopaedic Research, vol. 20, no. 1, pp. 40-50, 2002.

[81] J. J. Wilmot, D. J. Chiego, D. S. Carlson, C. T. Hanks, and J. J. Moskwa, "Autoradiographic study of the effects of pulsed electromagnetic fields on bone and cartilage growth in juvenile rats," Archives of Oral Biology, vol. 38, no. 1, pp. 67-74, 1993.

[82] S. Stolfa, M. Skorvánek, P. Stolfa, J. Rosocha, G. Vasko, and J. Sabo, "Effects of static magnetic field and pulsed electromagnetic field on viability of human chondrocytes in vitro," Physiological Research, vol. 56, no. 1, article S45, 2007.

[83] C. H. Hsieh, M. C. Lee, J. J. Tsai-Wu et al., "Deleterious effects of MRI on chondrocytes," Osteoarthritis and Cartilage, vol. 16, no. 3, pp. 343-351, 2008.

[84] Q. C. Yan, N. Tomita, and Y. Ikada, "Effects of static magnetic field on bone formation of rat femurs," Medical Engineering \& Physics, vol. 20, no. 6, pp. 397-402, 1998.

[85] S. Xu, N. Tomita, K. Ikeuchi, and Y. Ikada, "Recovery of smallsized blood vessels in ischemic bone under static magnetic field," Evidence-Based Complementary and Alternative Medicine, vol. 4, no. 1, pp. 59-63, 2007.

[86] T. Kondo, Y. Fukushima, H. Kon, and P. Riesz, "Effect of shear stress and free radicals induced by ultrasound on erythrocytes," Archives of Biochemistry and Biophysics, vol. 269, no. 2, pp. 381-389, 1989.

[87] L. B. Feril and T. Kondo, "Biological effects of low intensity therapeutic ultrasound in vitro: the potentials for therapy and the implications on safety of diagnostic ultrasound," International Congress Series, vol. 1274, pp. 133-140, 2004.

[88] Z. Zhang, J. Huckle, C. Francomano, and R. J. S. Spencer, "The effects of pulsed low-intensity ultrasound on chondrocyte viability, proliferation, gene expression and matrix production," Ultrasound in Medicine \& Biology, vol. 29, no. 11, pp. 16451651, 2003.

[89] G. I. Hasanova, S. E. Noriega, T. G. Mamedov, S. G. Thakurta, J. A. Turner, and A. Subramanian, "The effect of ultrasound stimulation on the gene and protein expression of chondrocytes seeded in chitosan scaffolds," Journal of Tissue Engineering and Regenerative Medicine, vol. 5, no. 10, pp. 815-822, 2011.

[90] A. R. Raveling, S. K. Theodossiou, and N. R. Schiele, “A 3D printed mechanical bioreactor for investigating mechanobiology and soft tissue mechanics," MethodsX, vol. 5, pp. 924932, 2018.

[91] K. D. Jorgenson, D. A. Hart, R. Krawetz, and A. Sen, "Production of adult human synovial fluid-derived mesenchymal stem cells in stirred-suspension culture," Stem Cells International, vol. 2018, Article ID 8431053, 16 pages, 2018.

[92] A. Lavrentieva, T. Hatlapatka, A. Neumann, B. Weyand, and C. Kasper, "Potential for osteogenic and chondrogenic differentiation of MSC," Advances in Biochemical Engineering/Biotechnology, vol. 129, pp. 73-88, 2012. 
[93] A. L. van Wezel, "Growth of cell-strains and primary cells on micro-carriers in homogeneous culture," Nature, vol. 216, no. 5110, pp. 64-65, 1967.

[94] R. Chen, S. J. Curran, J. M. Curran, and J. A. Hunt, “The use of poly(l-lactide) and RGD modified microspheres as cell carriers in a flow intermittency bioreactor for tissue engineering cartilage," Biomaterials, vol. 27, no. 25, pp. 4453-4460, 2006.

[95] T. L. Baker and T. J. Goodwin, "Three-Dimensional Culture of Bovine Chondrocytes in Rotating-Wall Vessels," In Vitro Cellular \& Developmental Biology - Animal, vol. 33, no. 5, pp. 358-365, 1997.

[96] J. Malda and C. G. Frondoza, "Microcarriers in the engineering of cartilage and bone," Trends in Biotechnology, vol. 24, no. 7, pp. 299-304, 2006.

[97] A. T. Lam, J. Li, J. P. Toh et al., "Biodegradable poly- $\varepsilon$-caprolactone microcarriers for efficient production of human mesenchymal stromal cells and secreted cytokines in batch and fed-batch bioreactors," Cytotherapy, vol. 19, no. 3, pp. 419432, 2017. 